\title{
Congenital Megaprepuce: A New Alternative Technique for Surgical Correction
}

\author{
Jovelino Q. Leao, Luiz G. Freitas Filho, Adriano L. Gomes, Antonio C. Heinsich, Jose \\ Carnevale
}

Division of Urology (JQL, LGFF, ALG, ACH, JC), Darcy Vargas Children's Hospital, Sao Paulo, and Division of Pediatric Surgery (LGFF), Federal University of Sao Paulo, Sao Paulo, Brazil

\begin{abstract}
Objective: To present a new alternative technique for surgical treatment of congenital megaprepuce.

Materials and Methods: From April 2004 to April 2006, five patients aged 2 to 5 years were treated using the new technique. The technique is described and illustrated. It differs from other techniques in that it takes into consideration the constant ballooning of the foreskin, which gives to the external genitalia the aspect of a penoscrotal transposition. Cosmetic and functional success were also assessed by a case review.

Results: After a follow-up of 1 to 3 years, all patients have normal voiding and a satisfactory cosmetic aspect.

Conclusion: This new technique could be a useful alternative in treatment of the congenital megaprepuce.
\end{abstract}

Key words: penis; children; foreskin; congenital abnormalities; surgery

Int Braz J Urol. 2008; 34: 313-8

\section{INTRODUCTION}

Congenital megaprepuce is a malformation consisting of a great redundancy of the inner preputial skin over a normal penile shaft and glans. The prepuce is not retractable and a ballooning of the foreskin is produced during the micturition. It was first described by O'Brien et al., in 1994 (1), and, since then, other authors have shown that although a rare condition, it is often confused with buried, trapped, concealed, webbed or micropenis (1-3).

The exuberant inner prepuce closed by the preputial ring creates a reservoir with a large dimension, leading to the anatomical aspect of penoscrotal transposition (Figure-1 and 2). Compression of the penile shaft results in urine spillage (Figure-3). The diagnosis is made, therefore, essentially by physical examination, which does not require functional exploration (4).

The objective of this report was to present a new alternative surgical technique that takes in account the penoscrotal transposition aspect of the malformation, which permits a satisfactory cosmetic appearance.

\section{MATERIALS AND METHODS}

From April 2004 to April 2006, five patients, aged 2 to 5 years, were treated using the technique.

The initial skin incision is shown in Figure-4. Then two traction stitches are made in the ventral point of the preputial ring, disassembling the foreskin and penile shaft, transforming the broken line incision in a 


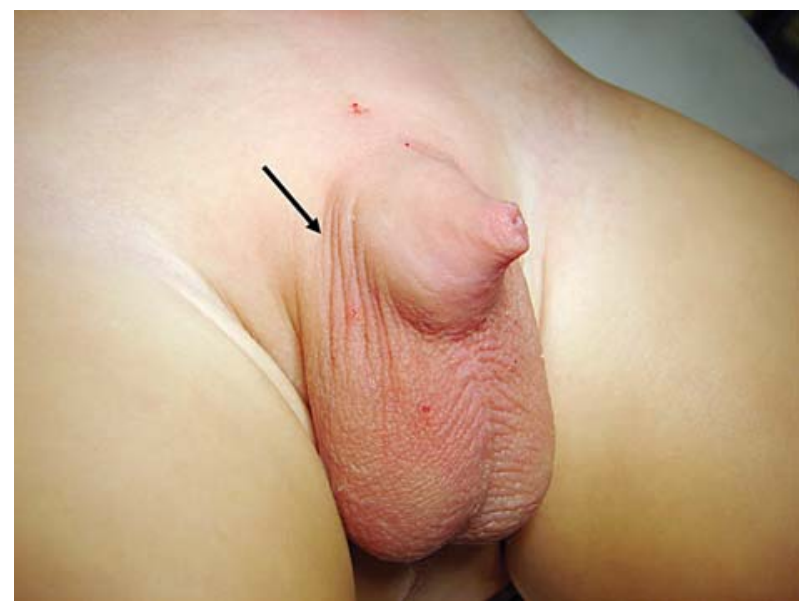

Figure 1 - The arrow shows an aspect of penoscrotal transposition in a patient with megaprepuce.

vertical straight line, as shown in Figure-5. The inner preputial skin is partially resected (Figure-6) and the foreskin is incorporated into the penile shaft with no flap required (Figure-7 and 8).

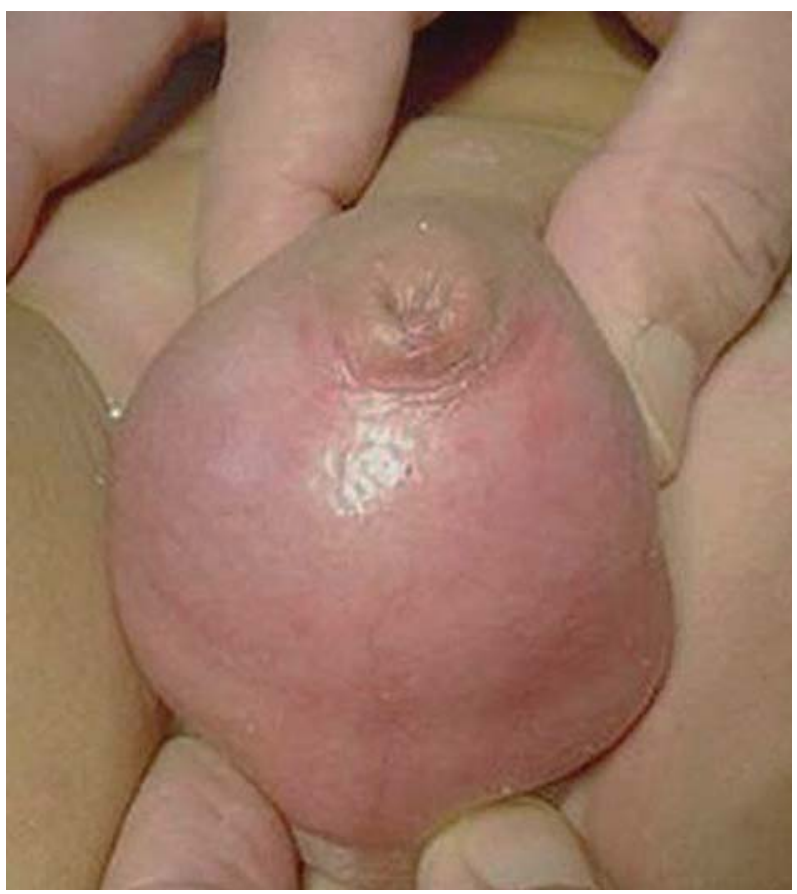

Figure 2 - Typical penoscrotal ballooning of the congenital megaprepuce.

\section{RESULTS}

All patients presented with the diagnosis of buried penis and 4 out of 5 have had repeated urinary tract infections. After the surgical treatment all patients have normal voiding pattern and the cosmetic aspect was considered adequate 1 to 3 years after surgery (Figure-8 and 9).

\section{COMMENTS}

Congenital megaprepuce was first described by O'Brien et al. (1). It is caused by a redundant inner prepuce over a preputial ring, which is not retractable, leading to a ballooning of the foreskin. Chronically it creates a reservoir, which renders the external genitalia an aspect of a penoscrotal transposition.

In agreement with other authors we believe that the condition is almost always confused with buried, trapped, concealed, webbed or micropenis. We postulate, however, that other previously reported surgical techniques have not considered the penoscrotal aspect of the genitalia, chronically distended by the accumulation of urine (1-6) (Figures-2 and 3).

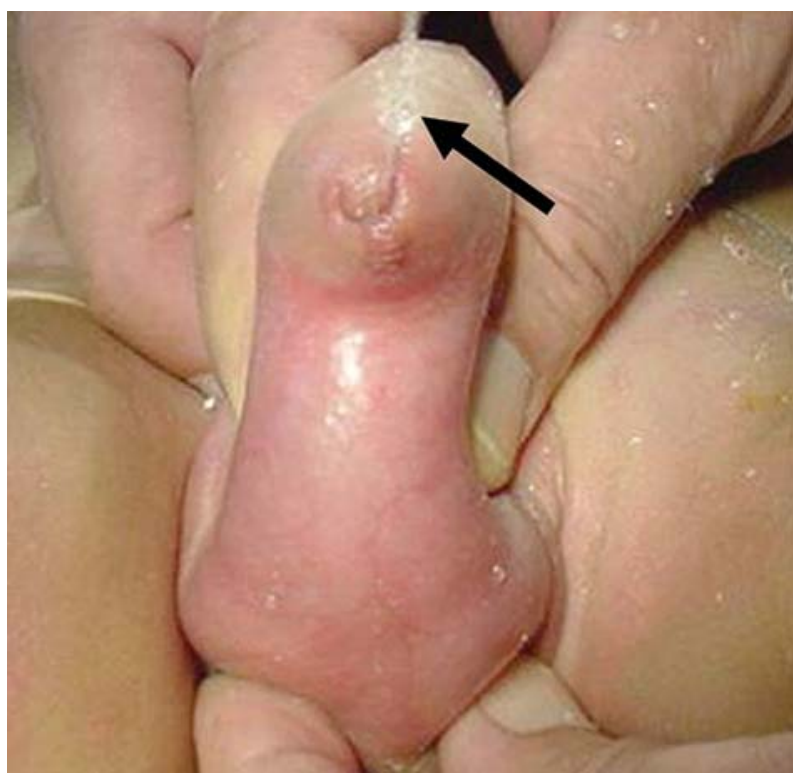

Figure 3 - The arrow shows the urinary jet flow when the foreskin is squeezed. 


\section{Congenital Megaprepuce: Surgical Correction}

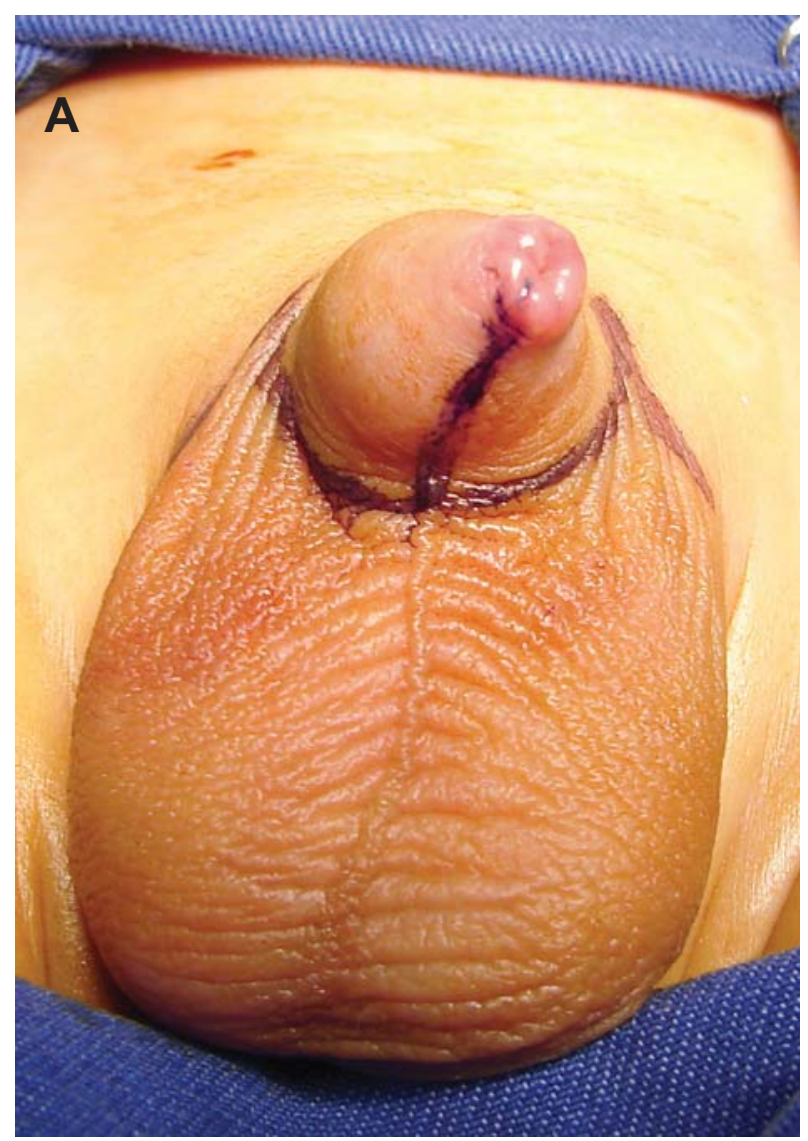

\section{B}

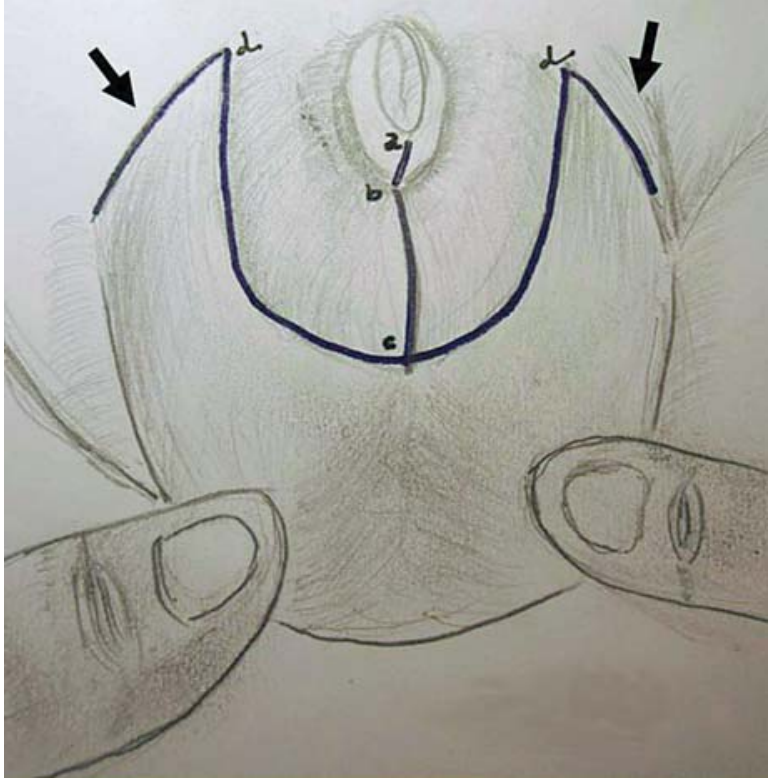

Figure 4-A) Correction o penoscrotal transposition. B) Schematic drawing. Arrows show the lateral incisions. 


\section{Congenital Megaprepuce: Surgical Correction}
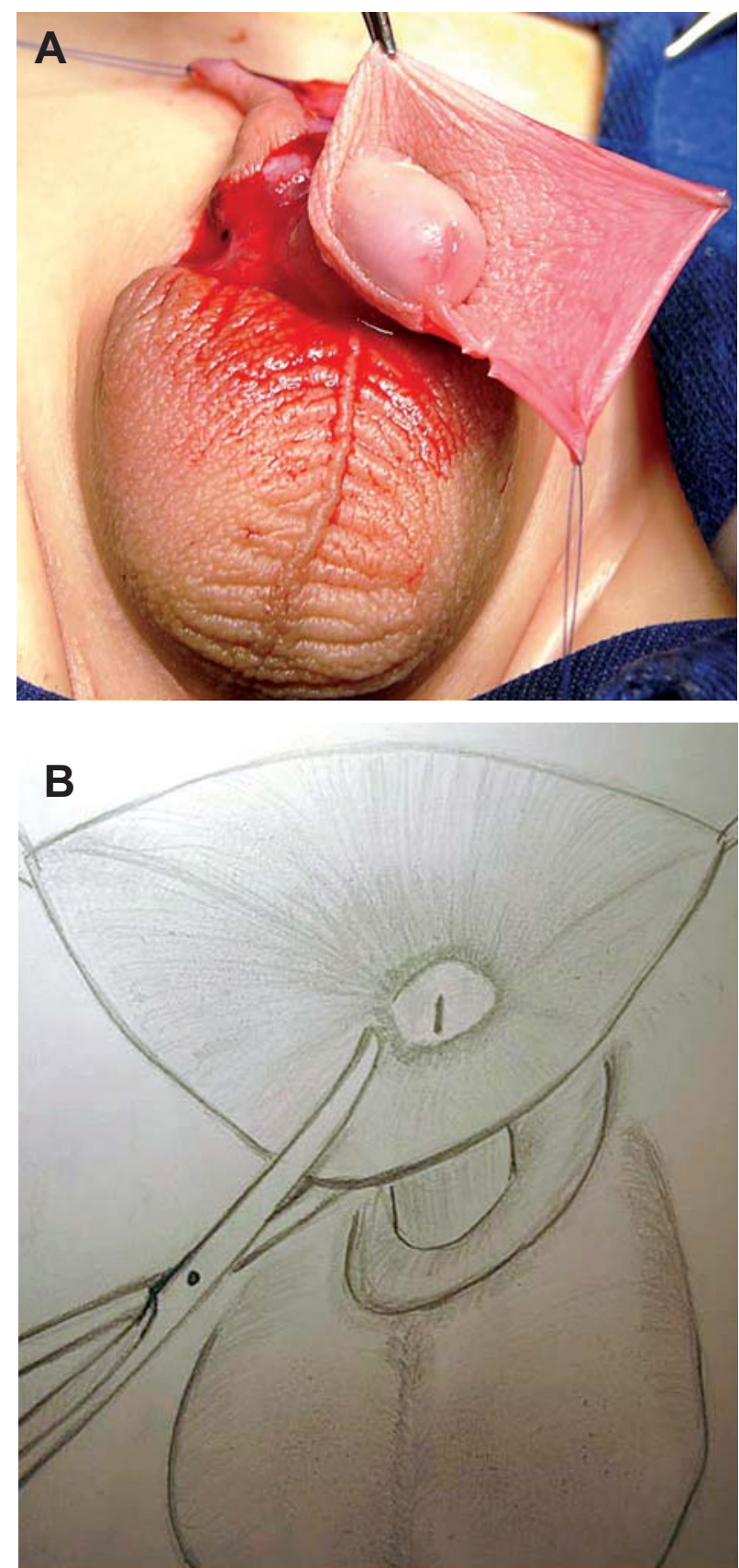

Figure 6-A) Cutting the inner prepuce. B) Schematic drawing.

Unlike other published series all our patients but one presented with a urinary tract infection (17).

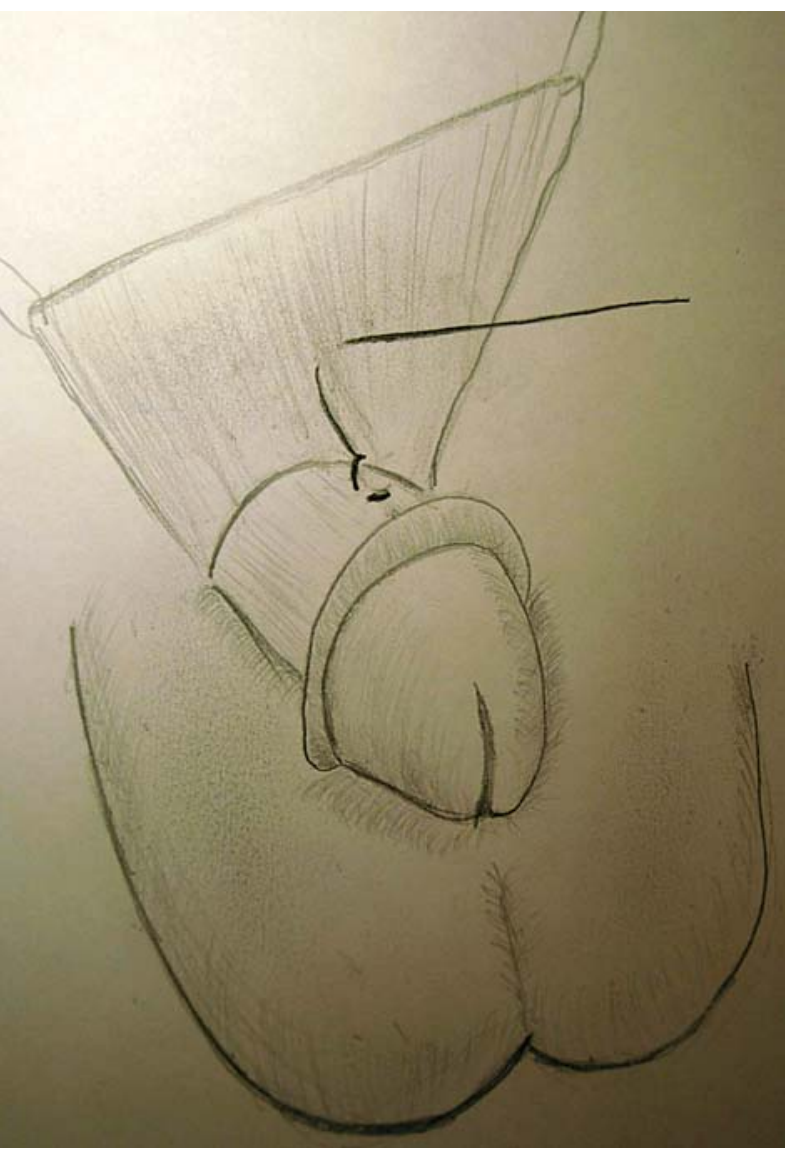

Figure 7 -Stitches incorporate the foreskin to the penile shaft.

As reported by Summerton et al. (3) we disagree with Popis and Crapp (7) that early circumcision cures the problem because this would remove the basic skin required to resurface the penile shaft.

The surgical technique presented in this study is aimed at correcting the penoscrotal transposition in addition to the resection of the redundant inner prepuce.

Although the present series included only five patients, we believe, as in the series of Summerton et al. (3), that when the immediate postoperative aspect is cosmetically treated, the long term results will be satisfactory 

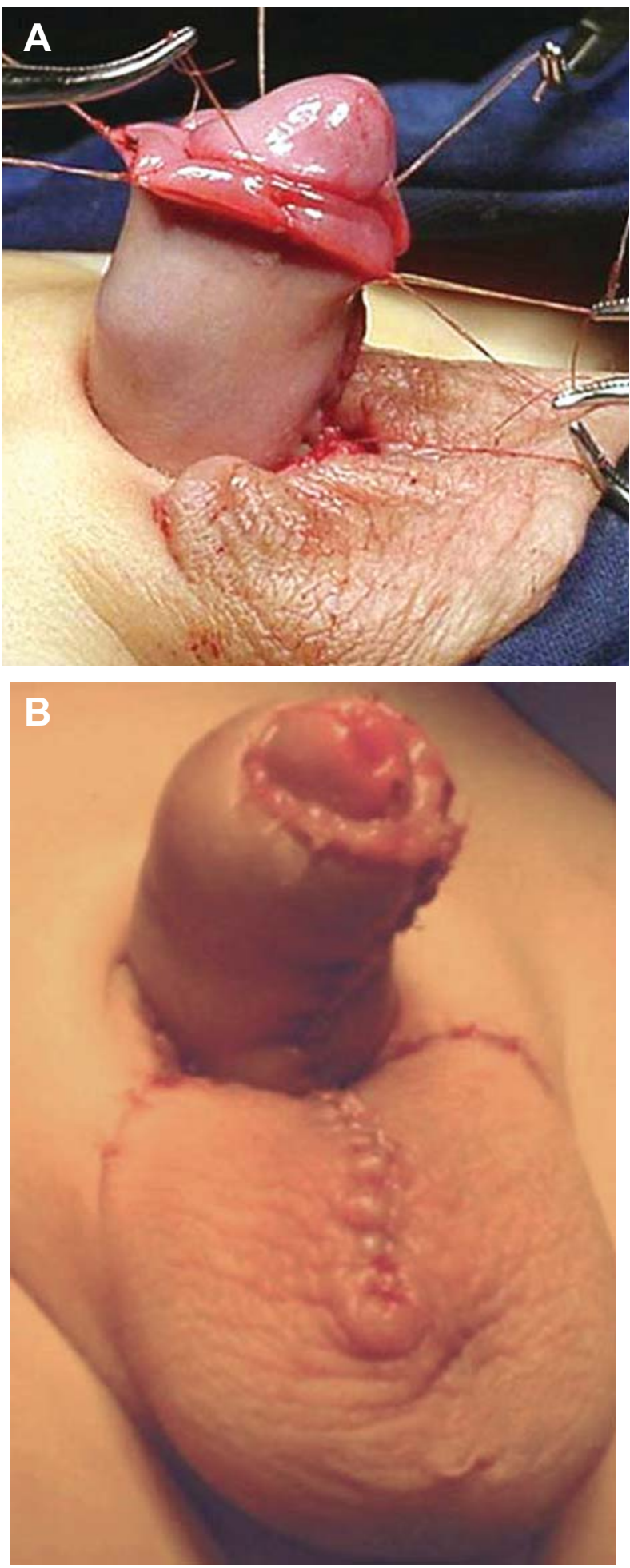

Figure $8-A$ ) and B) Postoperative surgical aspect.

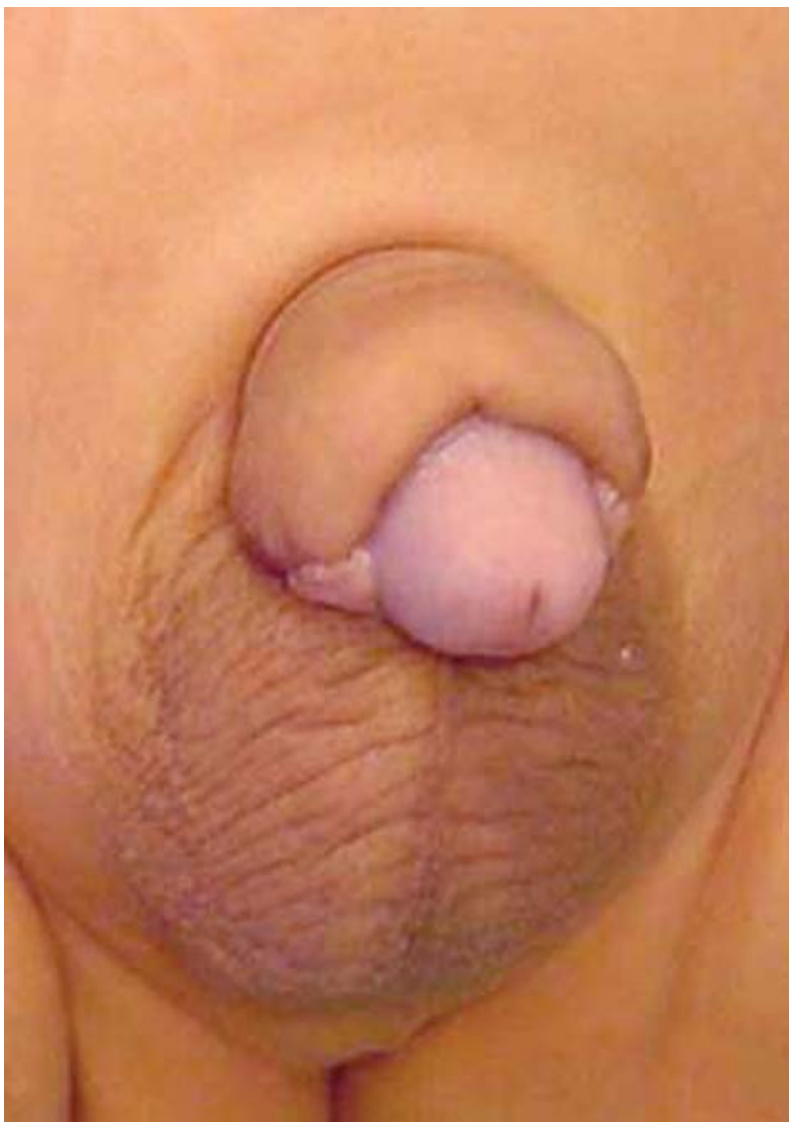

Figure 9 - Postoperative aspect 18 months after surgical correction.

\section{CONFLICT OF INTEREST}

None declared.

\section{REFERENCES}

1. O'Brien A, Shapiro AMJ, Frank JD: Phimosis or congenital megaprepuce? Br J Urol 1994; 73:719-20.

2. Shenoy MU, Rance CH: Surgical correction of congenital megaprepuce. Pediatr Surg Int. 1999; 15: 5934.

3. Summerton DJ, McNally J, Denny AJ, Malone PS: Congenital megaprepuce: an emerging condition--how to recognize and treat it. BJU Int. 2000; 86: 519-22. 


\section{Congenital Megaprepuce: Surgical Correction}

4. Delgado O, Dominguez H, Serrano D, Estornell M, Martinez V, Garcia I: Megaprepucio congenito: diagnostico y manejo terapeutico. Actas Urol Esp. 2006; 30: 1038-42.

5. Philip I, Nicholas JL: Congenital giant prepucial sac: case reports.J Pediatr Surg. 1999; 34: 507-8.
6. Ferro F, Spagnoli A, Spyridakis I, Atzori P, Martini L, Borsellino A: Surgical approach to the congenital megaprepuce. J Plast Reconstr Aesthet Surg. 2006; 59: 1453-7.

7. Powis MR, Capps S: Preputial intussusception or acquired megaprepuce. Pediatr Surg Int. 1998; 13: 158-9.

Correspondence address:

Dr. Luiz G. Freitas Filho

Rua Batista Cepelos, 87 / 61

04109-120, São Paulo, SP, Brazil

E-mail: 1freitasf@terra.com.br 